\title{
Differentiation of Multipotent Adult Germline Stem Cells Derived from Mouse Testis into Functional Endothelial Cells
}

\author{
I-Fen Cheng Diana Kaiser Daniela Huebscher Gerd Hasenfuss Kaomei Guan \\ Katrin Schäfer \\ Department of Cardiology and Pulmonary Medicine, University of Goettingen, Goettingen, Germany
}

\section{Key Words}

Endothelial progenitor cells $\cdot$ Fetal liver kinase-1 •

Multipotent adult germline stem cells $\cdot$ Vascular endothelial growth factor $\cdot$ Vasculogenesis

\begin{abstract}
Pluripotent stem cells hold great promise for the treatment of cardiovascular disease. We previously described multipotent adult germline stem cells (maGSCs) from mouse testis with differentiation potential similar to embryonic stem cells. The aim of this work was to differentiate maGSCs into functional endothelial cells and to study their potential for vasculogenesis. MaGSCs were cocultivated with OP9 stromal cells to induce differentiation into cardiovascular progenitors, i.e. fetal liver kinase 1-positive $\left(\mathrm{Flk}^{-1^{+}}\right)$cells. Five days later, Flk $-1^{+}$cells were separated using fluorescence-activated cell sorting, followed by cultivation on collagen type IV under endothelial differentiation conditions. At different time points, maGSC-derived endothelial-like cells were characterized using RT-PCR, flow cytometry, immunofluorescence and functional assays. Cultivation of Flk-1+ ${ }^{+}$cells resulted in the progressive upregulation of endothelial cell markers, including VE-cadherin, von Willebrand factor and endothelial nitric oxide synthase. Moreover, Flk-1+ maGSCderived endothelial-like cells were able to branch and form networks in vitro and promoted functional blood vessel for-
\end{abstract}

mation in vivo. Importantly, Flk-1+ cells retained their potential to proliferate and could be continuously expanded, while the ability of contact inhibition was preserved. Thus, maGSCs may provide a useful source of endothelial-like cells to study the basic mechanisms of vasculogenesis or endothelial differentiation.

Copyright $\odot 2012$ S. Karger AG, Base

\section{Introduction}

Endothelial injury or dysfunction plays a critical role in the development and progression of vascular disease states including thrombosis, atherosclerosis or ischemia. The limited availability and low proliferation potential of mature endothelial cells (ECs) constitutes a major obstacle in restoring dysfunctional endothelium or repairing ischemic tissues by transplantation of mature ECs [1]. Previous studies have shown that endothelial progenitor cells (EPCs), which may be isolated from peripheral human blood and represent approximately $0.004 \%$ of mononuclear cells, can be cultivated to generate proliferating ECs [2]. However, since cardiovascular risk factors including diabetes [3] and obesity [4] have been shown to impair the

K.G. and K.S. share the corresponding authorship.

Dr. Katrin Schäfer, Dr. Kaomei Guan

Department of Cardiology and Pulmonary Medicine, University of Goettingen Robert Koch Strasse 40, DE-37099 Goettingen (Germany)

Tel. +4955139 8921, E-Mail katrin.schaefer@med.uni-goettingen.de

kguan@med.uni-goettingen.de 
functional capacities of EPCs, their application and autologous transplantation for the regeneration of dysfunctional endothelium may be limited. Embryonic stem cells (ESCs) are a promising source of EPCs due to their capacity for self-renewal and pluripotency [5], and endothelial differentiation of ESCs has been demonstrated in vitro and in vivo [6,7]. Despite the potential of ESCs as a cellular source in tissue regeneration, ethical and immunological problems still limit their therapeutic application.

We have previously shown that spermatogonial stem cells (SSCs) isolated from adult mouse testis are able to acquire ESC properties under in vitro culture conditions [8]. These so-called multipotent adult germline stem cells (maGSCs) have the potential to give rise to different cell types of all 3 germ layers. However, a sufficient degree of differentiation has to be present in order to achieve effective tissue regeneration using stem cells, and protocols have yet to be developed to establish lineage selection for the use of pluripotent stem cells in organ regeneration strategies. So far, maGSCs have been shown to further differentiate into functional cardiomyocytes [9], neurons $[10,11]$, and male germ cells [12], whereas the generation of ECs from maGSCs has not been systematically studied. Fetal liver kinase (Flk)-1 is one of the earliest differentiation marker for ECs [13], and its expression has previously been used to identify the mesoderm-restricted potential of ESCs [14]. Moreover, Flk-1-positive $\left(\right.$ Flk-1 $\left.{ }^{+}\right)$cells derived from ESCs have been identified as cardiovascular progenitor cells and studied in endothelial differentiation [15-17]. In this study, we described a cultivation protocol to isolate and expand Flk- $1^{+}$cells from maGSCs, and examined their potential to morphologically and functionally differentiate into the endothelial lineage and to induce vasculogenesis.

\section{Methods}

\section{Cell Culture}

The mouse maGSC lines SSC5 and SSC15 used in this study were derived from Stra8-enhanced green fluorescent protein (EGFP)/Rosa26 double transgenic mice [18]. Undifferentiated SSC5 cells can be detected based on their GFP expression under control of the spermatogonia-specific promoter Stra8, whereas undifferentiated SSC15 cells are negative for GFP. The murine induced pluripotent stem cell line NE4O1, derived by overexpression of Oct4 in SSCs (unpubl. data), was used to test biological replication. maGSCs were initially grown on mitomycin-C-inactivated mouse embryonic fibroblast feeder cells, isolated from mouse embryo on day 14.5 and cultured in Dulbecco's modified Eagle's medium (DMEM; Invitrogen) in the presence of leukemia inhibitory factor $\left(10^{3}\right.$ units $\left./ \mathrm{ml}\right)$, as previously described $[8,9]$. In some experiments, murine endothelial cells (line SVEC4-10), cultivated in DMEM containing 10\% FBS and 4 mM L-glutamine, were used as a positive control. Human arterial smooth muscle cells (HASMC; Promocell), cultivated in SMC growth medium-2 (Promocell) containing 10\% FCS, $0.5 \mathrm{ng} / \mathrm{ml}$ epidermal growth factor, $2 \mathrm{ng} / \mathrm{ml}$ basic fibroblast growth factor and $5 \mu \mathrm{g} / \mathrm{ml}$ insulin, were used as a negative control.

\section{Generation and Isolation of Flk-1-Positive Cells}

To induce differentiation, $3 \times 10^{4}$ maGSCs ( $<30$ passages) per $100-\mathrm{mm}$ plate were cultured onto mitomycin-C-inactivated OP9 stromal cells in differentiation medium (Iscove's modified Dulbecco's medium (IMDM; Invitrogen) containing 20\% FCS, $1 \times$ nonessential amino acid (Invitrogen) and $450 \mu \mathrm{mol} / \mathrm{l}$ monothioglycerol (Sigma) for 5 days, with half of the medium changed on day 3. To obtain Flk- $1^{+}$progenitors, cells were harvested by brief incubation in $0.1 \%$ trypsin (w/v) $/ 0.01 \%$ EDTA (w/v). After preplating on $0.1 \%$ gelatin-coated dishes for $1 \mathrm{~h}$ to remove adherent OP9 cells, floating cells were collected and subjected to staining with PE-conjugated monoclonal anti-Flk-1 antibodies (dilution 1:100; BD Biosciences) for $30 \mathrm{~min}$ on ice, followed by fluorescence-activated cell sorting (FACS) and further cultivation as described below. Alternatively, and to establish the optimal extracellular matrix (ECM)-coating of culture dishes to support the growth and endothelial differentiation of the Flk- $1^{+}$progenitors, cells $\left(1 \times 10^{5}\right)$ were seeded on 60 -mm culture plates coated with either fibronectin (FN; concentration, $1.4 \mu \mathrm{g} / \mathrm{cm}^{2}$; Harbor Bio), collagen type IV (COLIV; concentration, $2.8 \mu \mathrm{g} / \mathrm{cm}^{2}$; Sigma), or growth-factor-reduced Matrigel (concentration, $11.6 \mu \mathrm{g} / \mathrm{cm}^{2}$; BD Biosciences), in differentiation medium with or without the addition of recombinant human vascular endothelial growth factor $\left(\mathrm{VEGF}_{165}\right.$; concentration, $10 \mathrm{ng} / \mathrm{ml}$; Peprotech) for up to 15 days.

\section{Endothelial Differentiation of FACS-Sorted Flk-1 ${ }^{+}$Cells}

To induce EC differentiation, $5 \times 10^{4}$ of FACS-sorted Flk- $1^{+}$ cells were cultured on COLIV-coated 6-well plates in endothelial differentiation medium, i.e. endothelial growth medium (EGM-2; PromoCell) supplemented with VEGF (50 ng/ml) with the medium being changed every 3 days. To expand maGSC-derived endothelial-like cells (maGSC-ECs), cells were grown to $80 \%$ confluence on days 12-13 and then subcultured (ratio 1:3) every 5 days.

\section{Reverse Transcription Polymerase Chain Reaction}

RNA was extracted using the SV Total RNA isolation kit (Promega). Reverse-transcription (RT) reactions were performed using the Transcriptor High Fidelity cDNA synthesis kit (Roche). A total of $200 \mathrm{ng}$ DNase-treated RNA was used for each RT reaction together with random hexamer primers (Roche). Polymerase chain reaction (PCR) analysis was performed with GoTaq Polymerase (Promega) using $1 \mu \mathrm{l}$ of the RT product per reaction. Primer sequences and conditions are shown in table 1 and had been established previously [18]. Of note, the number of PCR cycles for each set of primers was verified to be in the linear range of the amplification. Products were analyzed on $1.5 \%$ agarose gels and visualized by ethidium bromide.

\section{Real-Time Quantitative PCR}

Messenger RNA expression was quantified using $2 \mu \mathrm{l}$ of the RT reaction and the SYBR Green PCR master mix (Applied Biosystems). Quantitative analysis was achieved using GAPDH as an 
Table 1. Primer sequences and PCR conditions

\begin{tabular}{|c|c|c|c|c|}
\hline Gene & Primer sequence $\left(5^{\prime}\right.$ to $\left.3^{\prime}\right)$ & Size, bp & $\begin{array}{l}\text { Annealing } \\
\text { temperature, }{ }^{\circ} \mathrm{C}\end{array}$ & $\begin{array}{l}\text { Cycles } \\
\mathrm{n}\end{array}$ \\
\hline Brachyury & $\begin{array}{l}\text { F: GCTGTGACTGCCTACCAGAAT } \\
\text { R: GAGAGAGAGCGAGCCTCCAAA }\end{array}$ & 231 & 52 & 33 \\
\hline eNOS & $\begin{array}{l}\text { F: CCTTCCGCTACCAGCCAGA } \\
\text { R: CAGAGACCTTCACTGCATTGG }\end{array}$ & 105 & 60 & 35 \\
\hline Flk-1 & $\begin{array}{l}\text { F: CCTACCCCACACATTACATGG } \\
\text { R: TTTTCCTGGGCACCTTCTATT }\end{array}$ & 201 & 55 & 35 \\
\hline GAPDH & $\begin{array}{l}\text { F: GCAGTGGCAAAGTGGAGATT } \\
\text { R: TCTCCATGGTGGTGAAGACA }\end{array}$ & 250 & 56 & 31 \\
\hline Isl-1 & $\begin{array}{l}\text { F: ACGTCTGATTTCCCTGTGTGTTGG } \\
\text { R: TCGATGTGGTACACCTTAGAGCGG }\end{array}$ & 275 & 63 & 34 \\
\hline Mash-1 & $\begin{array}{l}\text { F: CTCGTCCTCTCCGGAACTGATG } \\
\text { R: CGACAGGACGCCGCGCTGAAAG }\end{array}$ & 301 & 64 & 38 \\
\hline Nkx-2.5 & $\begin{array}{l}\text { F: CAGTGGAGCTGGACAAAGCC } \\
\text { R: TAGCGACGGTTCTGGAACCA }\end{array}$ & 217 & 65 & 35 \\
\hline PECAM-1 & $\begin{array}{l}\text { F: GTCATGGCCGTCGAGTA } \\
\text { R: CTCCTCGGCATCTTGCTGAA }\end{array}$ & 261 & 55 & 35 \\
\hline SMA & $\begin{array}{l}\text { F: CTACTGCCGAGCGTGAGATT } \\
\text { R: GTAGACAGCGAAGCCAAGATG }\end{array}$ & 449 & 60 & 31 \\
\hline Sox-1 & $\begin{array}{l}\text { F: CCTCGGATCTCTGGTCAAGT } \\
\text { R: TACAGAGCCGGCAGTCATAC }\end{array}$ & 593 & 51.5 & 40 \\
\hline Tie-2 & $\begin{array}{l}\text { F: GTGAAGCCAGATGGGACAGT } \\
\text { R: TTGGCAGGAGACTGAGACCT }\end{array}$ & 499 & 60 & 32 \\
\hline VE-cad & $\begin{array}{l}\text { F: CCTTCTGCAGGGGACTATCGA } \\
\text { R: CATCTCATGCACCAGGGTCAC }\end{array}$ & 282 & 60 & 35 \\
\hline vWF & $\begin{array}{l}\text { F: TGGTGGGCATGATGGAGAGGTTA } \\
\text { R: GCAAGGTCACAGAGGTAGCTGACT }\end{array}$ & 485 & 65 & 38 \\
\hline
\end{tabular}

internal standard. Experiments were performed in triplicate in ABI PRISM ${ }^{\circledR} 7900$ HT real-time PCR system. The specificity of the amplification was verified by melting curve analyses, and results were analyzed by the comparative $C_{t}$ method [19].

\section{Flow Cytometry}

Cells were washed in PBS and fixed using either 4\% paraformaldehyde in PBS for $20 \mathrm{~min}$ at room temperature (for VE-cadherin visualization) or methanol:acetone (7:3 ratio) for $10 \mathrm{~min}$ at $-20^{\circ} \mathrm{C}$. After washing with PBS, cells were resuspended in $0.5 \%$ BSA (fraction V) in PBS at a concentration of $1 \times 10^{6}$ cells $/ \mathrm{ml}$ and incubated with polyclonal rabbit anti-mouse antibodies against platelet/EC adhesion molecule-1 (PECAM-1; dilution 1:20; SantaCruz Biotechnology), von Willebrand Factor (vWF; dilution 1:20; Dako), monoclonal rat anti-mouse antibodies against VE-cadherin (VE-cad; dilution 1:100; eBioscience), or monoclonal mouse anti-mouse antibodies against alpha smooth muscle cell actin $(\alpha-$ SMA; dilution 1:2,000; Sigma) for $45 \mathrm{~min}$ on ice, followed by incubation with Cy3- or MFP555-conjugated anti-rabbit, anti-rat or anti-mouse secondary antibodies (dilution 1:200; Molecular Probes) for $30 \mathrm{~min}$ in the dark. Each analysis included 10,000 total events.

maGSC-Derived Endothelial Cells

\section{Immunocytochemistry}

For the costaining of Flk-1 and Oct4, cells were fixed with 4\% paraformaldehyde in PBS for 20 min at room temperature. After washing 3 times with PBS, cells were permeabilized with $0.1 \%$ of Triton X-100 in 4\% BSA and blocked with $4 \%$ BSA for $30 \mathrm{~min}$. Cells were incubated with both goat anti-mouse Oct4 (dilution 1:50; R\&D Systems) and rat anti-mouse Flk-1 (dilution 1:100; BD 555307 ) at $37^{\circ} \mathrm{C}$ for $1 \mathrm{~h}$. After washing with PBS, cells were stained with fluorescein-isothiocyanate (FITC)-labeled anti-goat (dilution 1:200; Dianova) and Cy3-labeled anti-rat (dilution 1:200; Dianova), respectively.

For the staining of vascular cell markers, maGSC-ECs were seeded on COLIV-coated glass coverslips and fixed as described above. After washing with PBS, unspecific binding sites were blocked with $4 \% \mathrm{BSA}$ at $4^{\circ} \mathrm{C}$ overnight. Then, cells were incubated with either monoclonal rat anti-mouse VE-cad (dilution 1:100), polyclonal rabbit anti-mouse vWF (dilution 1:100), monoclonal or mouse anti-mouse $\alpha$-SMA (dilution 1:12,000) antibodies for $1 \mathrm{~h}$ at $37^{\circ} \mathrm{C}$, washed in PBS, followed by incubation with FITC-labeled anti-rat or anti-rabbit, or Cy3-labeled anti-mouse secondary antibodies (dilution 1:300, Jackson ImmunoResearch), respectively, for $40 \mathrm{~min}$ at $37^{\circ} \mathrm{C}$. Cell nuclei were visualized using 
4,6'-diamidino-2-phenylindole dihydrochloride (DAPI; $5 \mu \mathrm{g} / \mathrm{ml}$; Sigma).

For the analysis of acLDL uptake and lectin binding, cells were incubated with $2.5 \mu \mathrm{g} / \mathrm{ml}$ DiI-labeled acLDL (Molecular Probes) for $1 \mathrm{~h}$ at $37^{\circ} \mathrm{C}$, washed with PBS and fixed with $2 \%$ paraformaldehyde for $10 \mathrm{~min}$. They were then incubated with $10 \mu \mathrm{g} / \mathrm{ml}$ FITC-conjugated Griffonia (Bandeiraea) simplicifolia lectin (Vector; FL-1101), followed by nuclear staining with DAPI and analysis on a fluorescence microscope (Zeiss Axiovert 200).

\section{Proliferation Assay}

EC proliferation was measured using the CellTiter $96^{\circledR}$ AQueous One Solution Cell Proliferation Assay (MTS; Promega). Briefly, cells were plated at a density of $2 \times 10^{3}$ cells (in $100 \mu$ l medium) per well of a COLIV-coated 96-well plate. After cultivation for 24, 48, 72 or 96 h, respectively, $20 \mu \mathrm{l}$ of CellTiter $96^{\circledR}$ AQueous One Solution Reagent were added and incubated for an additional $2 \mathrm{~h}$ at $37^{\circ} \mathrm{C}$, and the spectral properties of the sample measured at $490 \mathrm{~nm}$.

\section{Contact Inhibition Assay}

HUVECs or maGSC-ECs $\left(9 \times 10^{4}\right.$ or $12 \times 10^{4}$ cells/well $)$ were seeded on COLIV-coated coverslips in a 24 -well plate and cultured for $24 \mathrm{~h}$ in cell type-dependent culture medium. BrdU labeling reagent (Zymed) was diluted 1:100 with culture medium and added to the cells. After incubation for an additional $2 \mathrm{~h}$ at $37^{\circ} \mathrm{C}$, cells were fixed with $70 \%$ ethanol for $20 \mathrm{~min}$ at $4^{\circ} \mathrm{C}$. BrdU incorporation was visualized using biotinylated, monoclonal antibodies against BrdU, followed by streptavidin peroxidase-conjugate and diaminobenzidine as chromogen, according to the manufacturer's protocol (BrdU staining kit; Zymed). The number of BrdUpositive cells was counted in 5 random microscope fields, and expressed as a percentage of total cells (out of approximately 500 total nuclei).

\section{Matrigel Angiogenesis Assay}

The angiogenic potential of FACS-sorted Flk- ${ }^{+}$, Flk- $1^{\text {low/- }}$ $\mathrm{GFP}^{-}$and Flk- $1^{-} / \mathrm{GFP}^{+}$cells or maGSC-ECs was examined by plating $1 \times 10^{4}$ cells in 96-well plates, precoated with $50 \mu \mathrm{l} \mathrm{ECMa-}$ trix $^{\mathrm{TM}}$ (Chemicon), as previously described [20]. FACS-sorted cells were incubated at $37^{\circ} \mathrm{C}$ for up to 15 days; maGSC-ECs were examined $8 \mathrm{~h}$ after cell seeding. The ability to form tubes, branch and develop vascular-like networks was manually determined in 5 randomly selected microscope fields $($ at $\times 100)$.

\section{Spheroid Angiogenesis Assay}

To generate spheroids, a total of $4 \times 10^{4}$ FACS-sorted cells were resuspended in $10 \mathrm{ml}$ medium containing $20 \%$ methylcellulose solution and incubated in round-bottom 96 -well plates (100 $\mu \mathrm{l} /$ well) at $37^{\circ} \mathrm{C}$ for $24 \mathrm{~h}$. Type I rat-tail collagen (BD Biosciences) was diluted $1: 1$ with $0.1 \%$ acetic acid, mixed with $10 \times$ M199 medium (in a ratio of 9:1), and neutralized with $0.2 \mathrm{~N} \mathrm{NaOH}$ immediately before use. Spheroids were harvested in methylcellulose solution supplemented with $20 \%$ FCS and gently diluted (1:1) with collagen working solution. Spheroid suspensions were distributed in duplicate into prewarmed 24 -well plates by adding $1 \mathrm{ml}$ (containing about 40 spheroids) to each well and incubating at $37^{\circ} \mathrm{C}$ for $30 \mathrm{~min}$. After solidification of the collagen, $100 \mu \mathrm{l}$ of medium were added to each well and incubated at $37^{\circ} \mathrm{C}$. Pictures of 20 spheroids at random microscope fields $(\times 200)$ were taken and evaluated using Zeiss AxioVision 3.1 software.

\section{In vivo Matrigel Plug Assay}

The assay was essentially performed as described in [21]. Briefly, $300 \mu$ l liquid Matrigel (BD Biosciences) were mixed at $4^{\circ} \mathrm{C}$ with $300 \mu \mathrm{l}$ of a methocel/fibrinogen/EC basal medium (1:1:1) mixture containing $5 \times 10^{5} \mathrm{CM}$-DiI-fluorescent-labeled cells (containing approximately 1,000 spheroids). VEGF and basic fibroblast growth factor $(100 \mathrm{ng} / \mathrm{ml}$ of each) were added and the mixture subcutaneously injected under the left or right dorsal flanks of anesthetized female CD1 mice. Per mouse, two plugs containing either maGSC-ECs, or negative (i.e. no cells or OP9 cells) or positive (i.e. SVEC4-10 cells) control cells, respectively, were injected. After 3 weeks, mice were anesthetized and carefully perfused with FITC-labeled lectin (70 $\mu$ l in $200 \mu \mathrm{l}$ PBS) through the jugular vein in order to demonstrate that newly formed vessels had connected to the host vasculature. Plugs were removed $15 \mathrm{~min}$ later and processed for histological analysis. Paraffin sections (30 $\mu \mathrm{m}$ thick) were counterstained with DAPI and analyzed under a fluorescence microscope. Quantitative analysis was performed by Image-Pro Plus (Media Cybernetics).

\section{Statistical Analysis}

Results are presented as mean \pm standard deviation (SD). The number of independent experiments performed is indicated in the text. Differences between groups were compared using 1-way ANOVA followed by Bonferroni's multiple comparison tests using GraphPad Prism software, version 4.01. A p value $<0.05$ was considered statistically significant.

\section{Results}

The experimental setup explaining the strategy employed to obtain $\mathrm{Flk}-1^{+}$cardiovascular progenitors from maGSCs and to differentiate these cells into functional ECs is depicted in figure 1a. MaGSCs were cocultivated with stromal cells (OP9) to induce differentiation into cardiovascular progenitors, i.e. Flk- $1^{+}$cells. In preliminary experiments, the Stra8-GFP ${ }^{+}$maGSC line SSC5 was used to establish the coculture system. These experiments revealed that about $85 \%$ of the cells were positive for GFP, indicating their undifferentiated state as explained in the Methods section, and $6.3 \%$ were positive for Flk-1 before initiation of the coculture (day 0 ). The distribution of 3 separate cell populations, i.e. Flk- $1^{+}, \mathrm{Flk}-1^{\text {low/-}} / \mathrm{GFP}^{-}$and Flk-1 ${ }^{-} / \mathrm{GFP}^{+}$cells, was examined using antibodies against Flk-1 and flow cytometry (fig. 1b). Time course analysis revealed that cocultivation of maGSCs on OP9 stromal cells for 5 days yielded the highest amount of Flk- $1^{+}$cells (39\%), compared to cocultivation for either 4 (27\%; p < $0.05)$ or $6(26 \%$; p < 0.05$)$ days, respectively (fig. 1c). Moreover, the percentage of Flk- $1^{\text {low/- }} / \mathrm{GFP}^{+}$decreased from $55 \%$ on day 4 to $25 \%$ on day 6 . Of note, only a small subpopulation of Flk- $1^{+}$cells was found to also be positive for GFP $\left(9.7 \pm 4.1 \%\right.$ of the Flk- $1^{+}$population and $3.5 \pm 1.5 \%$ of the 

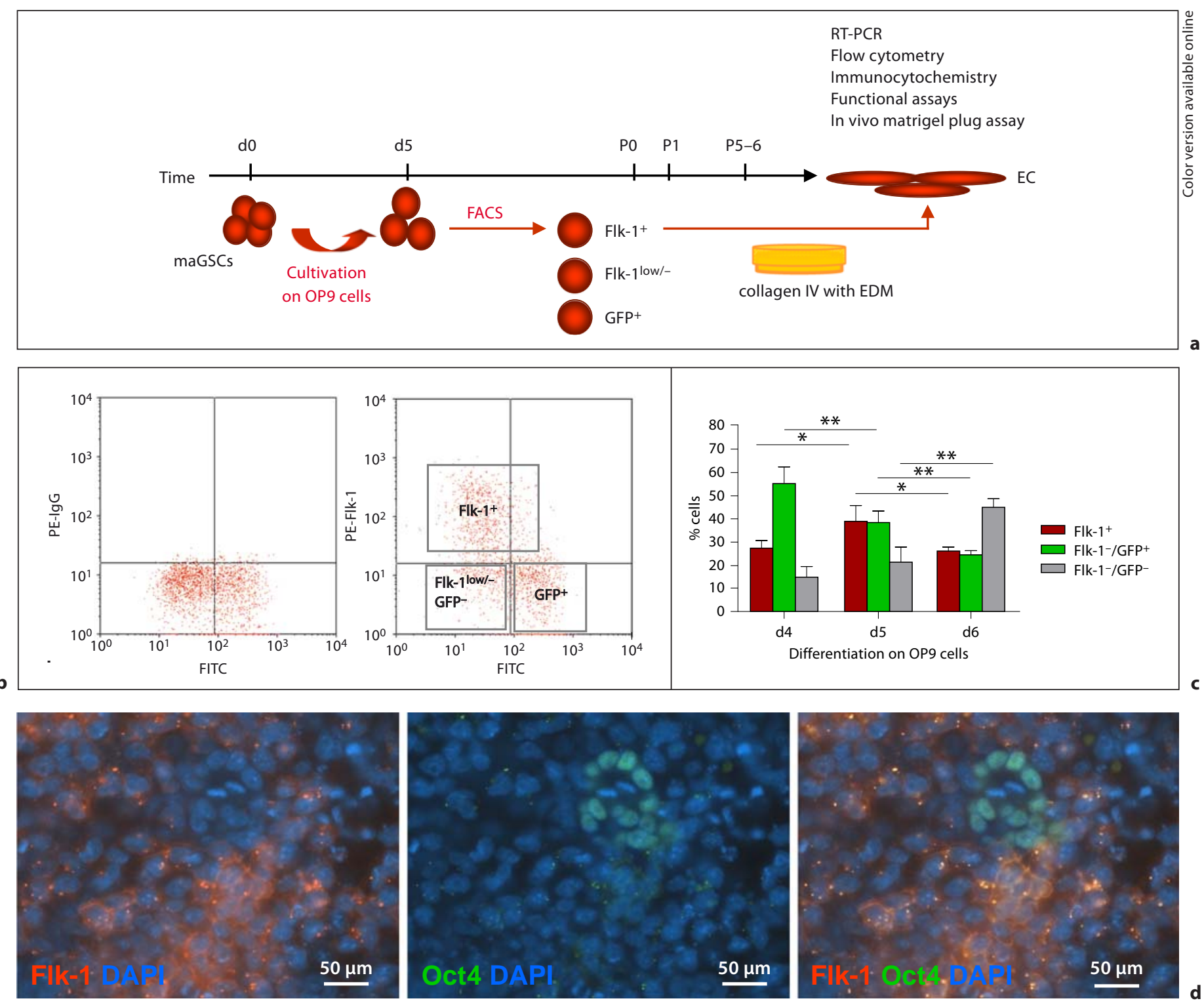

Fig. 1. Generation of Flk-1 $1^{+}$cells from maGSCs. a Schematic drawing depicting the strategy of Flk- $1^{+}$cell generation. Flk- $1^{+}$cells were separated using FACS after cultivation of maGSCs on OP9 cells for 5 days (d5), followed by endothelial differentiation in endothelial differentiation medium (EDM). At different time points, the EC character was examined as indicated. $\mathbf{b}$ Representative dot plots of cell suspensions after coculture on OP9 stromal cells for 5 days and staining with either isotype control (left) or anti-Flk-1

total cell population, respectively). Immunocytochemical analysis using cells derived from the maGSC line SSC15 confirmed that the majority of Flk- $1^{+}$cells were negative for the pluripotency marker Oct4 (fig. 1d). Thus, maGSCs were cocultivated on OP9 stromal cells for 5 days in all subsequent experiments. Following pre-differentiation of antibodies (right). c Results of the quantitative analysis of 3 different cell populations detected, based on the level of Flk-1 or GFP expression, are shown. $\mathrm{d}=$ Day; $\mathrm{P}=$ passage. ${ }^{*} \mathrm{p}<0.05,{ }^{* *} \mathrm{p}<0.01$. d Immunocytochemical detection of Flk-1 (red signal, left panel) and the stem cell marker Oct4 (green signal, middle panel; merge, right panel). Cell nuclei were visualized using DAPI (blue). For colors, see online version

maGSCs on OP9 cells for 5 days, cells were separated by FACS based on their Flk-1 expression and immediately used for further characterization. Of note, the purity of the cells after sorting was $98.2 \pm 0.7 \%$ for Flk- $1^{+}$cells, $96.3 \pm$ $2.6 \%$ for Flk- $1^{\text {low } /-} / \mathrm{GFP}^{-}$and $97.7 \pm 1.2 \%$ for $\mathrm{Flk}-1^{-} / \mathrm{GFP}^{+}$ cells. RT-PCR analysis of RNA isolated from cells imme- 
Fig. 2. Characterization of FACS-separated Flk- $1^{+}$cells. a RNA was isolated from Flk- $1^{+}$, Flk- $1^{\text {low/- }} / \mathrm{GFP}^{-}$and $\mathrm{GFP}^{+}$cells immediately after FACS separation and used to determine the expression of mesoderm lineage markers Flk-1, Tie-2, brachyury, Isl-1, Nkx-2.5, the neural progenitor markers Mash-1 and Sox-1, as well as the housekeeping gene GAPDH. Day 0 (d0) undifferentiated maGSCs and OP9 stromal cells served as a negative control. The angiogenic potential of $\mathrm{Flk}-1^{+}, \mathrm{Flk}-1^{\text {low/- }} / \mathrm{GFP}^{-}$ and $\mathrm{GFP}^{+}$cells was analyzed using the Matrigel (b) as well as the spheroid (c) angiogenesis assay. Findings in Flk-1 ${ }^{+}$cells as well as the quantitative analysis of 3 independent experiments are represented. \#\#\# $\mathrm{p}<0.001$.
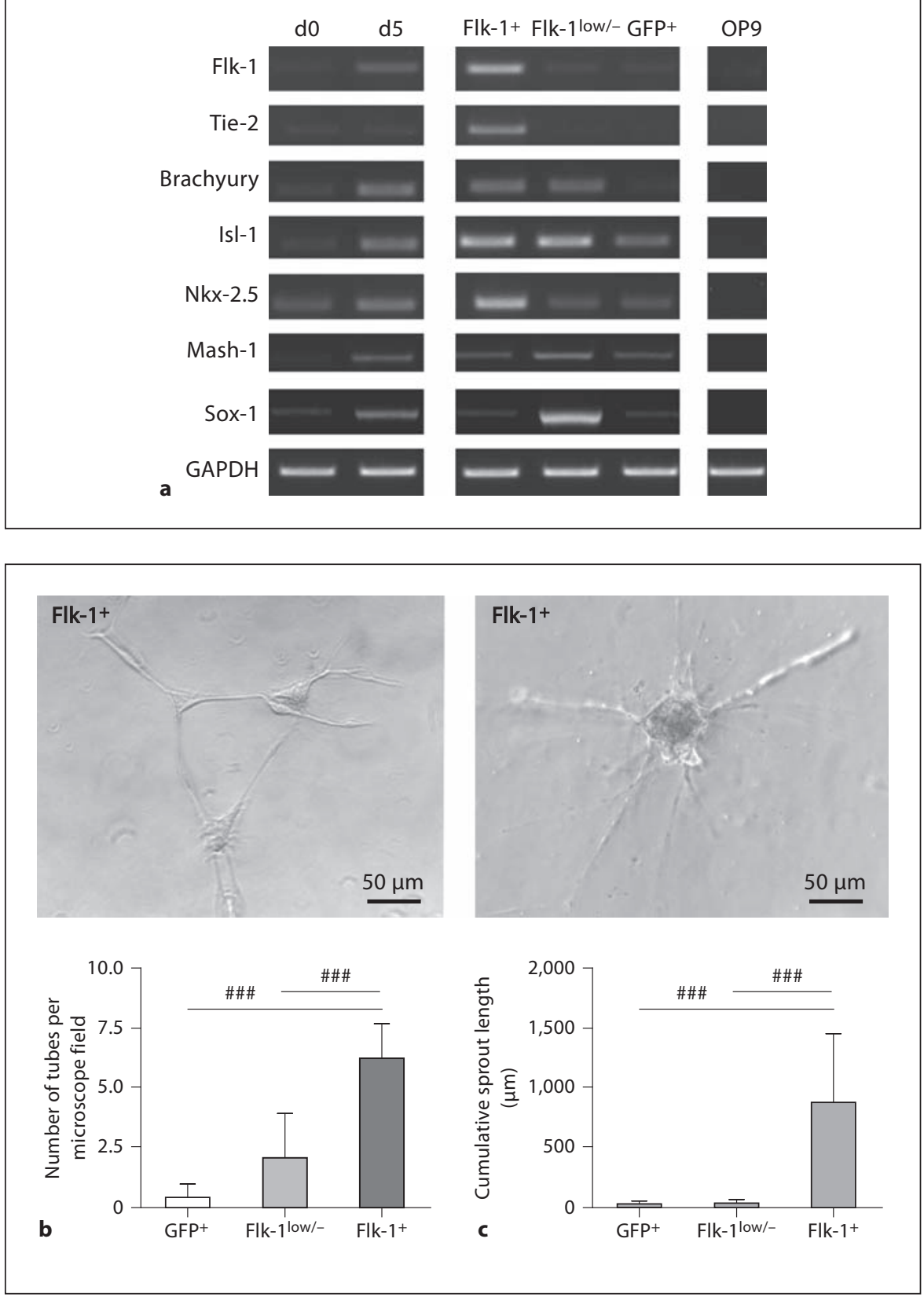

diately after FACS separation confirmed that Flk-1 $1^{+}$cells (but neither Flk-1 $1^{\text {low- }-/ G F P}{ }^{-}$nor Flk-1 $1^{-} / \mathrm{GFP}^{+}$cells), express mRNA for Flk-1 or other endothelial or cardiac progenitor cell markers, such as the receptor for angiopoietin (Tie-2), as well as brachyury, Isl-1 or Nkx-2.5 (fig. 2a). Since Flk-1 is also expressed in neural progenitor cells [22], the neural progenitor markers Mash-1 and Sox-1 were also examined, revealing low Mash-1 and Sox-1 mRNA levels within the Flk $-1^{+}$cell population. Moreover, analysis of their angio- genic properties in vitro revealed that Flk- $1^{+}$cells exhibited the highest capacity to form cord-like structures and networks after being seeded on Matrigel ( $\mathrm{p}<0.001$ vs. Flk$1^{\text {low/- } / \mathrm{GFP}^{-}}$or $\mathrm{GFP}^{+}$cells; fig. $2 \mathrm{~b}$ ). Similarly, only Flk $-1^{+}$ cells were able to sprout when cultured in type I collagen

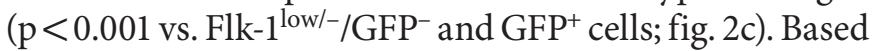
on these findings, maGSCs-derived, FACS-sorted Flk-1 ${ }^{+}$ progenitor cells were used for further endothelial differentiation. 
Before initiating endothelial differentiation of the FACS-sorted Flk- $1^{+}$cells, the effect of coating culture dishes with either COLIV, FN or growth-factor-reduced Matrigel was compared, with regard to their ability to support growth and endothelial lineage differentiation. As shown in online supplementary figure I (see www. karger.com/doi/10.1159/000332910 for all online suppl. figures), the cultivation of cells for an additional 5 days without VEGF supplementation was associated with a significant reduction of the number of Flk- $1^{+}$cells, although to a lesser extent if cells had been grown on COLIV. If cells had been grown on COLIV in the presence of VEGF (10 ng/ml), $36 \pm 3.3 \%$ of them were positive for Flk-1, i.e. a percentage similar to the initial Flk- $1^{+}$population. Furthermore, real-time quantitative PCR revealed that cells grown on COLIV in the presence of VEGF expressed significantly higher amounts of Tie-2 and the endothelial marker VE-cad in comparison to cells grown on FN or growth-factor-reduced Matrigel (online suppl. fig. IIA-C). Although vWF mRNA expression was similar in cells grown on different ECM proteins (online suppl. fig. IID), vWF immunopositive tube-like structures were only observed in cells cultured on either FN or COLIV (online suppl. fig. IIIA). Finally, cells grown on COLIVcoated culture dishes exhibited the highest ability to sprout, as assessed using the spheroid angiogenesis assay (online suppl. fig. IIIB). Thus, FACS-separated Flk-1 ${ }^{+}$ cells were seeded on COLIV-coated culture dishes and cultivated in the presence of VEGF to induce endothelial differentiation.

At different time points after cultivation, cells were collected for RNA isolation followed by RT-PCR analysis ( $\mathrm{n}=3$ independent experiments; fig. $3 \mathrm{a}$ and online suppl. fig. IV). These analyses revealed that with prolonged duration of culture (up to passage 6), mRNA expression of mature EC markers, i.e. vWF, VE-cad and eNOS, continued to increase, particularly in the Flk- $1^{+}$cells, whereas mRNA expression of markers for vascular smooth muscle cells (e.g. $\alpha$-SMA) decreased. Compared to Flk- $1^{\text {low/- }}$ $\mathrm{GFP}^{-}$and $\mathrm{GFP}^{+}$cell populations, higher expression of Tie-2, PECAM-1, VE-cad, eNOS, and vWF mRNA was observed in Flk- $1^{+}$cells. Similarly, the morphology of Flk$1^{+}$cells changed from 'spindle-shaped' on day 1 after replating (day $5+1$; fig. 3b, left panel) to a 'cobblestone-like' EC morphology after longer culture, i.e. after being passaged (fig. 3b, middle and right panel). Also, cells retained their ability to proliferate, as shown by the increasing density of colonies (a typical example is shown in fig. 3b, right panel) as well as in the MTS assay (fig. 3c). On the other hand, contact inhibition of growth also could be observed on confluent maGSC-ECs, similar to HUVEC (used as positive control; fig. 3d). These 'cobblestone-like' cells were thus termed maGSC-ECs.

To further characterize maGSC-ECs after being cultivated for up to 6 passages, flow cytometry was performed using antibodies against markers expressed by mature ECs, i.e. VE-cad and vWF (fig. 4a). Approximately 53 and $66 \%$ of cells were found to express VE-cad or vWF, respectively, whereas less than $15 \%$ of cells were positive for $\alpha$-SMA. Immunostaining of cells confirmed expression of VE-cad at adherent junctions between ECs, whereas vWF antigen was detected predominantly in the perinuclear cytoplasm (fig. 4b, left column). Of note, OP9 feeder-layer cells examined in parallel were found to be negative in these analyses (fig. 4b, right column). Moreover, cells were able to endocytose acLDL and to bind mouse EC-specific lectin (fig. 5a). To analyze their functional capacities, the spheroid and Matrigel angiogenesis assays were employed. These analyses revealed that cells were able to form cord-like structures and networks within 8 $\mathrm{h}$ after being plated on Matrigel (fig. $5 \mathrm{~b}$ ) or to sprout within $48 \mathrm{~h}$ after being mixed with collagen type I, similar to the murine EC line SVEC4-10 (fig. 5c).

To examine the functionality of culture-derived maGSC-ECs in vivo, CM-DiI-fluorescent labeled cells were mixed with Matrigel and injected subcutaneously under the dorsal skinfold of CD1 mice. As shown in figure 6a, only a few FITC-lectin-positive cells could be detected in both negative control groups, i.e. Matrigel only (without cells) and Matrigel/OP9 stromal cells, 3 weeks after injection, whereas numerous FITC-lectin-positive blood vessels (thus demonstrating their connection with the host vasculature) were detectable in Matrigel plugs mixed with murine endothelial SVEC4-10 cells or maGSC-ECs, respectively. Quantitative evaluation confirmed that the addition of maGSC-ECs to the Matrigel plug was associated with enhanced neovascularization (fig. 6b).

\section{Discussion}

In this study, we established a protocol for the isolation and differentiation of endothelial-like cells from maGSCs. We show that a 5-day coculture of undifferentiated maGSCs on the bone marrow stromal cell line OP9, followed by FACS-mediated selection of Flk- $1^{+}$cells and cultivation on COLIV under VEGF-mediated lineage induction, reproducibly yielded functional and proliferating ECs. The endothelial phenotype of the culture-de- 


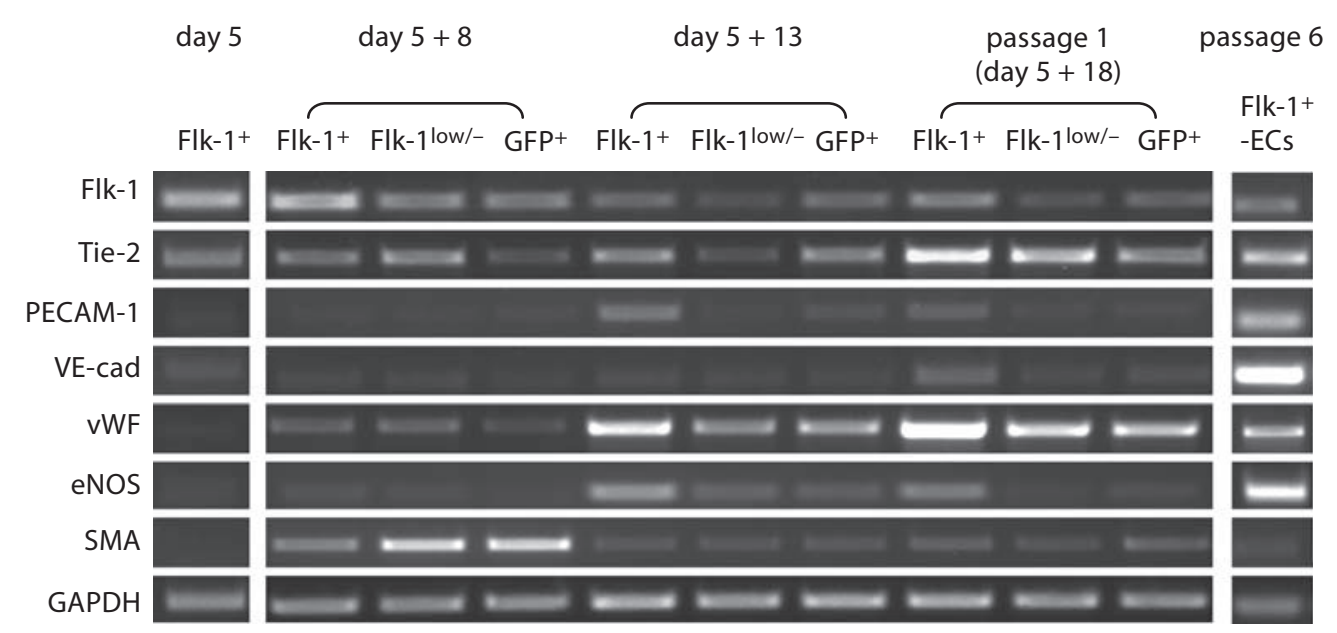

a

b
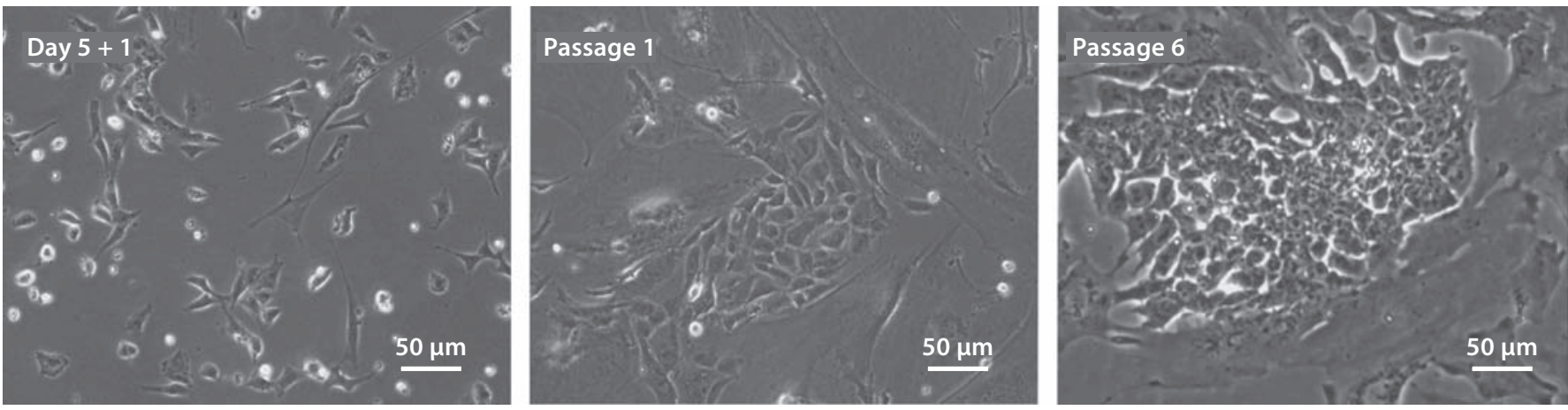

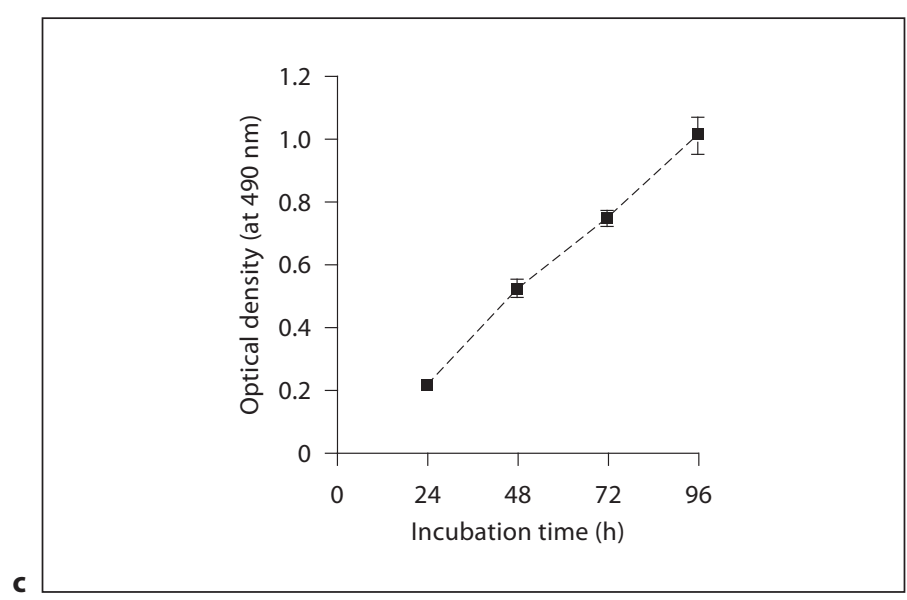

Fig. 3. Differentiation of maGSC-derived Flk-1 ${ }^{+}$cells into endothelial-like cells. a The mRNA expression profile of endothelial lineage markers at different time points after cultivation was determined by RT-PCR. Flk-1 ${ }^{+}$cells differentiated into endotheliallike cells after long-term culture (i.e. passage 6) as suggested by the upregulation of the endothelial-specific markers VE-cad, vWF or eNOS. The quantitative analysis of these findings is shown in online supplementary figure IV. b Phase contrast microscopy revealed a 'spindle-shaped' appearance of Flk-1 $1^{+}$cells 1

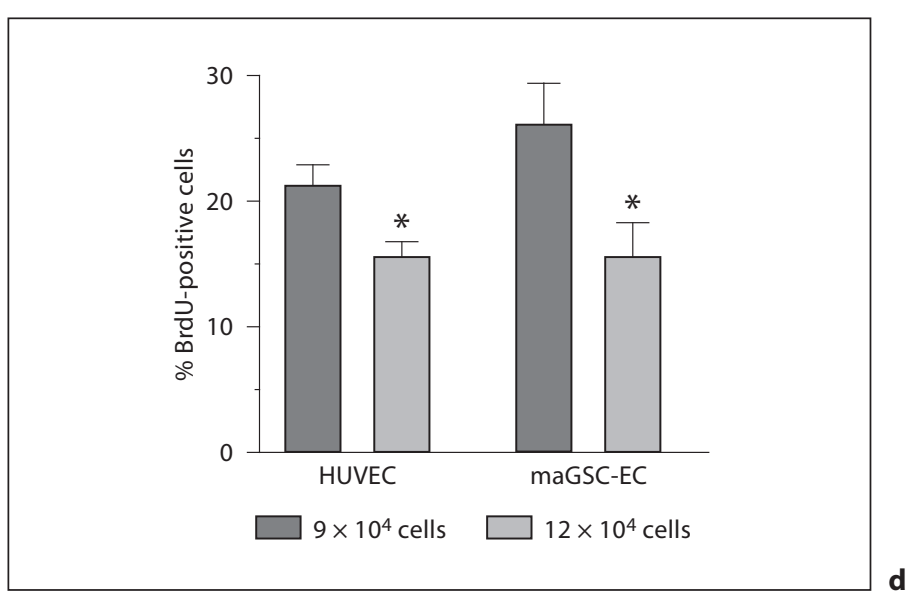

day after culture in endothelial differentiation medium (EDM; left panel) and cobblestone-like cell clusters at passage 1 (middle panel), whereas Flk- $1^{+}$cells formed larger clusters after long-term culture (right panel). c The ability of maGSC-ECs at passage 6 to proliferate was examined using the MTS assay. d The ability of maGSC-ECs or HUVEC to undergo contact inhibition was investigated after analysis of BrdU incorporation $24 \mathrm{~h}$ after being seeded on COLIV-coated culture slides at 2 different cell densities. ${ }^{*} \mathrm{p}<0.05$ versus $9 \times 10^{4}$ cells. 


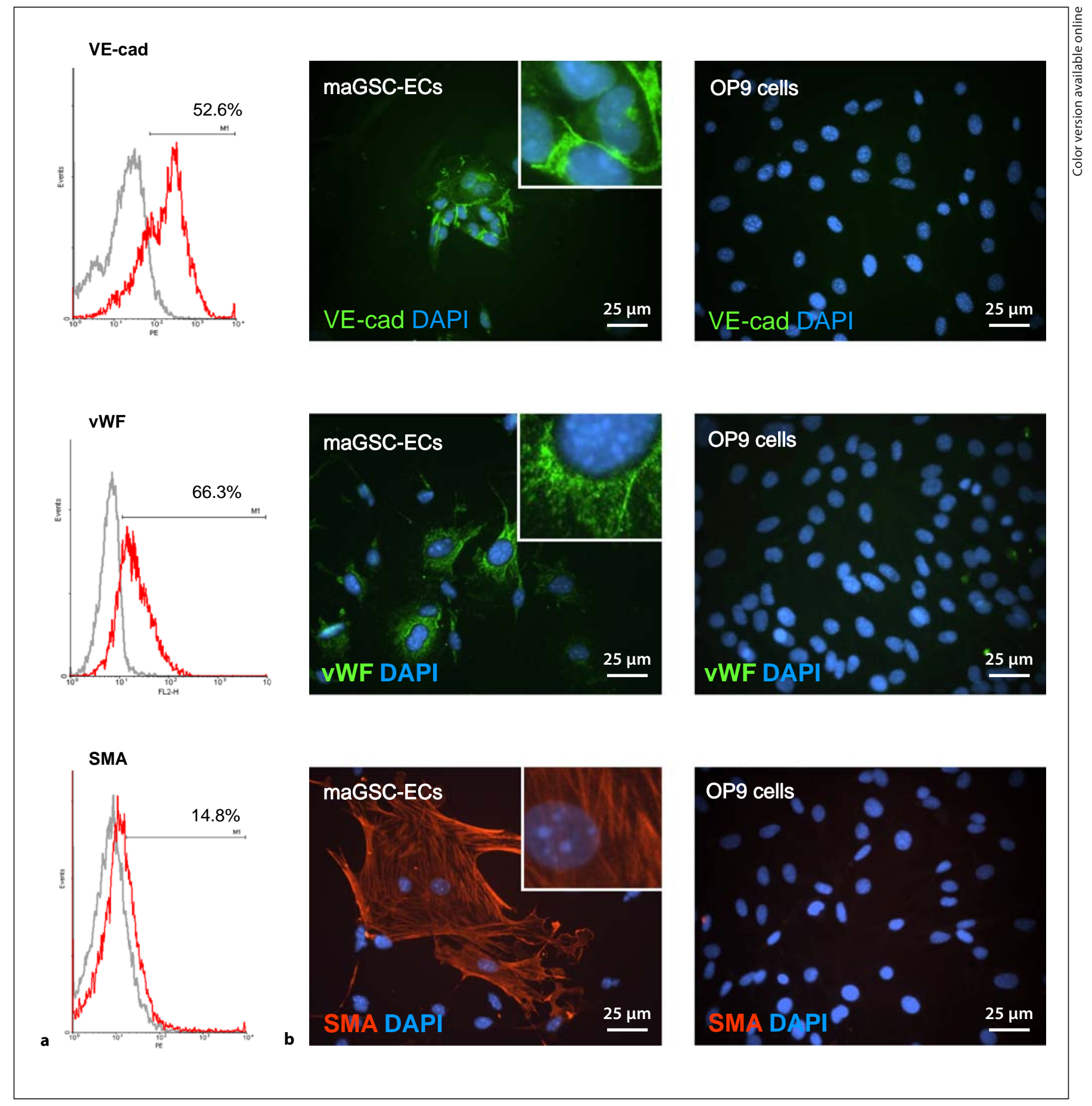

Fig. 4. Vascular cell marker expression by maGSC-ECs. a Flow cytometry indicated that approximately 53 or $66 \%$ of cultured maGSC-ECs at passage 6 were positive for VE-cad or vWF, respectively, whereas $15 \%$ of the cells expressed the smooth muscle cell marker $\alpha$-SMA. b Immunocytochemical staining of maGSC-
EC monolayers at passage 6 revealed VE-cad expression at cell junctions, whereas vWF was detected in the perinuclear cytoplasm and $\alpha$-SMA in the cytoskeleton. See insets for higher magnification. OP9 cells served as a negative control. 

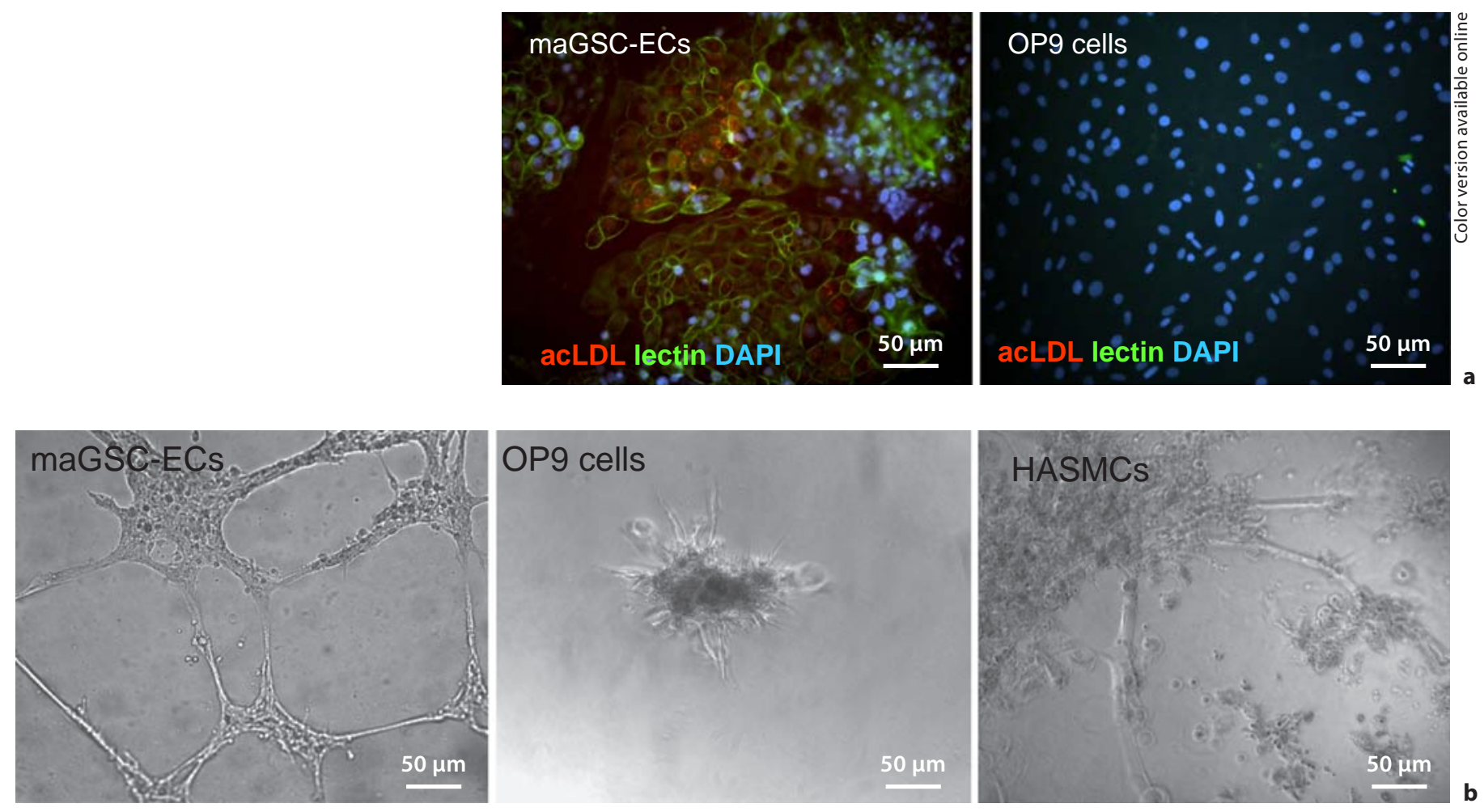

Fig. 5. Functional characterization of maGSC-ECs in vitro. a MaGSC-ECs (passage 6) were able to uptake fluorescencelabeled acLDL (red) and to bind mouse endothelium-specific lectin (green). DAPIpositive cell nuclei appear blue. b The Matrigel angiogenesis assay revealed that maGSC-ECs, but not OP9 stromal cells or HASMCs, possess the ability to form networks. c The spheroid angiogenesis assays showed that maGSC-ECs, and to a lesser extent also HASMC, have the ability to sprout. The mouse EC line SVEC4-10 was used as positive control and OP9 cells as negative control. For colors, see online version.
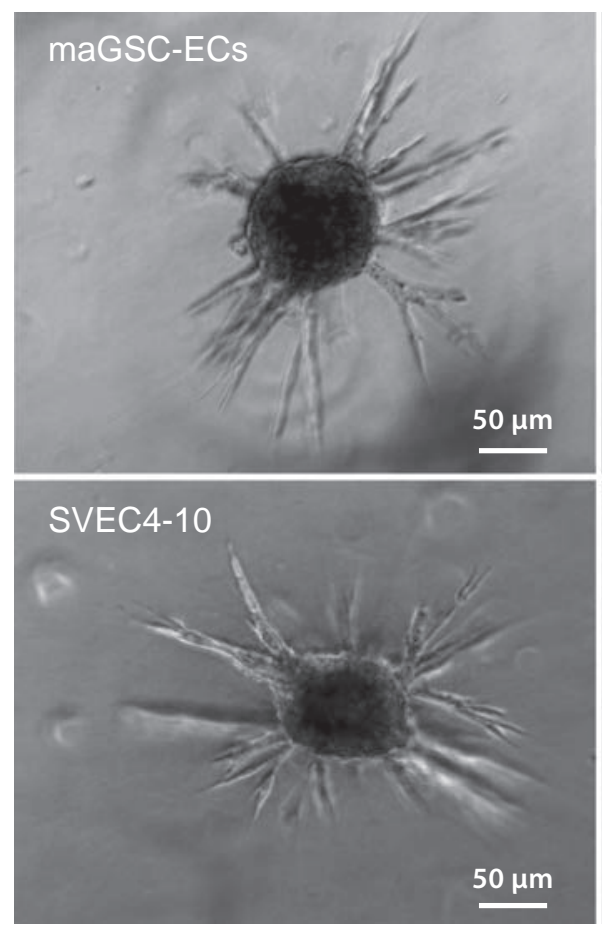

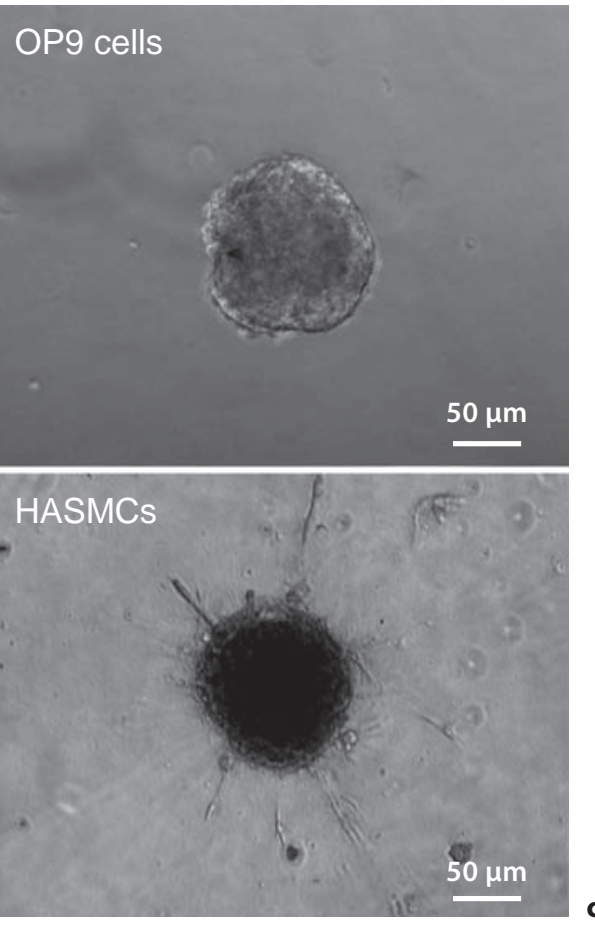



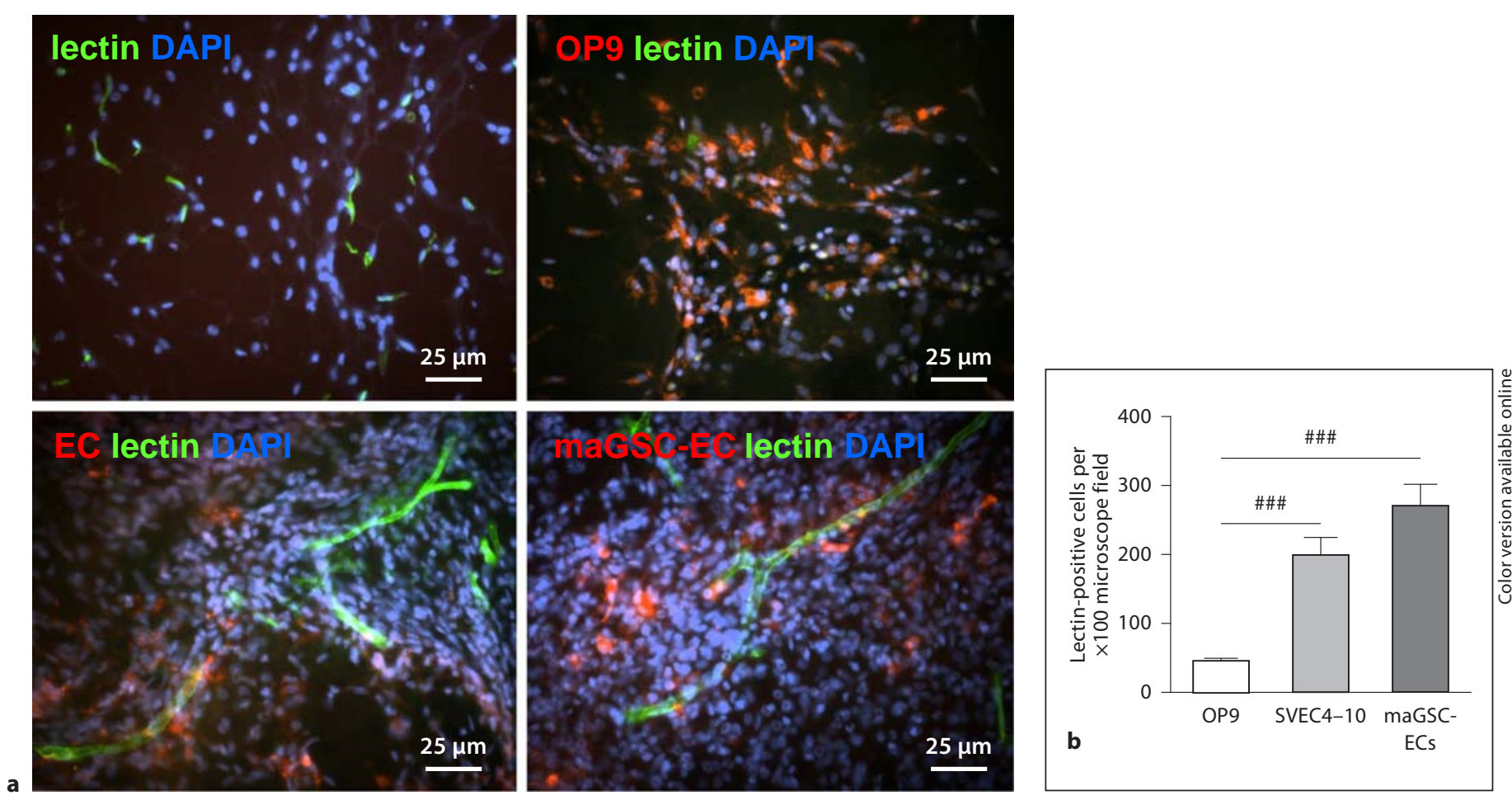

Fig. 6. Effect of maGSC-ECs on new blood vessel formation in vivo. a Distinct FITC-lectin-positive, i.e. perfused tube-like structures, could be observed in maGSC-ECs/Matrigel and positive control SVEC4-10/Matrigel plugs. Injection of plugs with
Matrigel only (without cells) or OP9 cells served as a negative control. b Quantitative analysis confirmed that maGSC-ECs were able to promote neovascularization to a similar extent as positive control cells (SVEC4-10). ${ }^{\# \#} \mathrm{p}<0.001$ versus OP9 cells. rived cells was demonstrated by their typical 'cobblestone' morphology, the expression of endothelial lineage markers, as well as the ability to sprout, branch and form vascular-like networks in vitro. Analysis of the kinetics of endothelial marker expression revealed successive maturation steps towards the EC lineage, with increasing levels of markers expressed on committed angioblasts (e.g. VE-cad) or mature ECs (e.g. vWF and eNOS). Importantly, endothelial-like cells derived from Flk- $1^{+}$cells could be stably propagated for at least 6 passages, expressed vWF and VE-cad, and supported new blood vessel formation in mice, although maGSC-ECs were only detected in close proximity, but not to directly incorporate into murine vascular structures.

The generation of adequate quantities of proliferating and functional ECs is an important prerequisite for cell-based therapies to improve blood flow and induce revascularization of ischemic tissues. Previous studies have shown that circulating EPCs isolated from human peripheral blood may differentiate into ECs and promote neovascularization in animal models $[23,24]$ or humans [25]. However, since the functional capacities of EPCs from subjects with diabetes [3], obesity [4], other cardiovascular risk factors and those with coronary artery disease [26] are often impaired, the feasibility of EPC for cell-based therapeutic strategies may be limited. Functional ECs may also be generated from human [27] and mouse pluripotent ESCs [6]; however, their application for regenerative therapies is restricted due to ethical and legal concerns or immunological problems. MaGSCs, which can be generated from murine testis and show pluripotency similar to mouse ESCs [18], may provide an interesting alternative if the technique could be also applied in humans. Moreover, transplantation of pluripotent cells for vascular repair can only be therapeutic if a sufficient degree of spontaneous vascular differentiation occurs. In this regard, only a few cells differentiated into vascular endothelial or smooth muscle cells were detected 4 weeks after the transplantation of undifferentiated maGSCs into the heart of immunesuppressed mice [9]. Therefore, protocols must be developed to establish efficient lineage selection before the 
use of pluripotent stem cells in organ regeneration strategies.

The receptor tyrosine kinase Flk-1 (VEGFR2) is one of the receptors for VEGF and has been widely used as marker for the selection of mesoderm-restricted progenitor cells. Several studies have shown that Flk- $1^{+}$cells derived from mouse ESCs may serve as cardiovascular progenitors and further differentiate into vascular endothelial and smooth muscle cells [7, 15, 28]. Our findings extend those previous studies by demonstrating that Flk$1^{+}$cells may also be obtained from maGSCs and can be induced to differentiate into proliferating endotheliallike cells. We show that Flk-1 $1^{+}$cells differentiated into morphological and functional endothelial-like cells in vitro and that the expression of endothelial lineage markers further increased during long-term cultivation of maGSC-ECs. Notably, $\alpha$-SMA mRNA and protein also were detected, consistent with the ability of Flk- $1^{+}$progenitors to differentiate into both endothelial and smooth muscle cells [29]. Previous studies have shown that VEGF supplementation promotes endothelial and PDGF induces smooth muscle cell differentiation [7], respectively. In our study, $\alpha$-SMA mRNA expression progressively decreased with further differentiation, suggesting that longer cultivation periods or higher concentrations of VEGF might be required to increase the purity of ECs. VEGF supplementation was also found to increase the number of Flk- $1^{+} /$PECAM- $1^{+}$cells, as determined by the comparison of maGSC on day 5 of predifferentiation on OP9 cells and maGSC-ECs after passage 3 (online suppl. fig. V). On the other hand, cooperation of both ECs and mural cells may be necessary for blood vessel formation [30].

Existing protocols for the generation of vascular cells from ESCs in culture either employ the formation of embryoid bodies or differentiation on COLIV matrix or stromal cells, such as OP9 [31-33], and comparison of both strategies suggested that the OP9 system may better support the maturation of ECs [34]. In line with these previous findings, an increased expression of Flk-1 and Tie- 2 could be observed after 5 days coculture on OP9 cells. In addition, we demonstrated that a FACS-mediated selection of Flk- $1^{+}$cells further enhanced the enrichment of endothelial-lineage committed cells. Although the upregulated expression of EC-related genes occurred in the absence of VEGF supplementation, secretion of factors promoting endothelial differentiation from the OP9 feeder layer might also have played a role. In addition to soluble mediators, components of the ECM may have influenced the differentiation potential of pluripotent stem cells. For example, COLIV is known to support both human [35] and mouse [7, 36] ESC differentiation into mesodermal cell lineage, and FN has been shown to promote the differentiation of CD34-positive human progenitors into ECs [37]. The comparison of different ECM proteins with respect to their ability to promote EC differentiation in this study revealed that cultivation on COLIV-coated plates yielded the highest amount of cells positive for Flk-1 and that cells grown on COLIV exhibited the highest angiogenic potential.

Regarding the potential of Flk- $1^{-}$cells to differentiate into ECs, as suggested previously [38], Flk-1 $1^{\text {low/- }}$ and to a lesser extent also $\mathrm{GFP}^{+}$cells were found to express Tie-2 and vWF mRNA, at least at early time points of cultivation. A possible cause for this observation includes the secondary expression of Flk-1 by initially Flk- $1^{-}$cells [15]. Of note, only Flk- $1^{+}$, but neither Flk-1 ${ }^{\text {low/- }}$ and $\mathrm{GFP}^{+}$, nor OP9 cells were found to express Flk-1 immediately after the FACS-mediated selection and they were also negative for Tie-2. Also, functional analyses in vitro revealed that only Flk- $1^{+}$cells were able to sprout or to form cord-like networks. Of note, a minority of Flk- $1^{+}$cells also expressed GFP immediately after sorting. On the other hand, immunostaining analysis confirmed that Flk $-1^{+}$cells were negative for the pluripotency marker Oct4. In agreement with previous reports, in which hemangioblast and angioblast were found to express Flk-1 as well as Oct3/4 [39], the Flk- $1^{+} / \mathrm{GFP}^{+}$cell population could thus also represent endothelial precursors. Nevertheless, the possibility of GFP ${ }^{+}$ undifferentiated cells exists and future studies will have to carefully evaluate these cells with regard to the possibility of teratoma formation. Of note, the significant reduction of BrdU incorporation and thus cell proliferation in confluent maGSC-ECs suggested that the capacity of contact growth inhibition is preserved.

Our results also show that mouse maGSCs are similar to mouse ESCs. When cocultured with OP9 cells for 5 days, they differentiated into Flk- $1^{+}$cells $(35 \%)$ with an efficiency similar to that seen in ESCs (41.6\%) [40]. The efficiency is also comparable to studies showing that mouse ESCs or induced pluripotent stem cells cultured on COLIV-coated dishes differentiate into Flk- $1^{+}$cells with an efficiency of 24 and $27 \%$, respectively [41, 42]. The finding that FACS-sorted Flk- $1^{+}$cells expressed the cardiovascular progenitor markers Isl-1, Nkx-2.5 and the early mesodermal marker brachyury (in line with a previous report [42]), and differentiate into beating cardiomyocytes during cultivation on OP9 cells (not shown), further supports that Flk- $1^{+}$cells derived from maGSCs are cardiovascular progenitors. On the other hand, markers 
of neural progenitor cells, also known to express Flk-1 [22], were found to be expressed at relatively low levels in the Flk- $1^{+}$cell population compared to Flk- $1^{\text {low/-}} / \mathrm{GFP}^{-}$or Flk- $1^{-} / \mathrm{GFP}^{+}$cells.

Taken together, our findings demonstrate that Flk- $1^{+}$ cardiovascular progenitor cells derived from mouse adult testis can be effectively expanded and differentiated into functional and proliferating endothelial-like cells using a relatively simple cultivation protocol. These findings suggest that maGSCs may represent an alternative source of ex-vivo-generated ECs that may be used to study basic mechanisms and molecular events involved in the regulation of EC differentiation and blood vessel formation.
Future studies will have to determine whether these cells incorporate into newly formed vessels in vivo and also their potential to safely promote angiogenesis, before they may be exploited for possible use in regenerative cell therapy or tissue-engineering applications.

\section{Acknowledgements}

The authors gratefully acknowledge the technical assistance of Sarah Barke, Anke Cierpka and Yvonne Hintz. The study was supported by a grant from the German Research Foundation (Deutsche Forschungsgemeinschaft, KFO 155, EN 84/21-1 and GU 595/2-1).

\section{References}

1 Tannock IF, Hayashi S: The proliferation of capillary endothelial cells. Cancer Res 1972; 32:77-82.

$\longrightarrow 2$ Hirschi KK, Ingram DA, Yoder MC: Assessing identity, phenotype, and fate of endothelial progenitor cells. Arterioscler Thromb Vasc Biol 2008;28:1584-1595.

3 Tepper OM, Galiano RD, Capla JM, et al: Human endothelial progenitor cells from type II diabetics exhibit impaired proliferation, adhesion, and incorporation into vascular structures. Circulation 2002;106:27812786.

4 Heida NM, Müller JP, Cheng IF, et al: Effects of obesity and weight loss on the functional properties of early outgrowth endothelial progenitor cells. J Am Coll Cardiol 2010;55: 357-367.

5 Vittet D, Prandini MH, Berthier R, et al: Embryonic stem cells differentiate in vitro to endothelial cells through successive maturation steps. Blood 1996;88:3424-3431.

-6 Li Z, Wu JC, Sheikh AY, et al: Differentiation, survival, and function of embryonic stem cell derived endothelial cells for ischemic heart disease. Circulation 2007;116:I46-I54.

7 Yamashita J, Itoh $\mathrm{H}$, Hirashima $\mathrm{M}$, et al: Flk1-positive cells derived from embryonic stem cells serve as vascular progenitors. $\mathrm{Na}-$ ture 2000;408:92-96.

8 Guan K, Wolf F, Becker A, Engel W, Nayernia K, Hasenfuss G: Isolation and cultivation of stem cells from adult mouse testes. Nat Protoc 2009; 4:143-154.

-9 Guan K, Wagner S, Unsöld B, et al: Generation of functional cardiomyocytes from adult mouse spermatogonial stem cells. Circ Res 2007;100:1615-1625.

10 Glaser T, Opitz T, Kischlat T, et al: Adult germ line stem cells as a source of functional neurons and glia. Stem Cells 2008;26:24342443 .
11 Streckfuss-Bömeke K, Vlasov A, Hulsmann $S$, et al: Generation of functional neurons and glia from multipotent adult mouse germ-line stem cells. Stem Cell Res 2009;2:139-154.

12 Nolte J, Michelmann HW, Wolf M, et al: PSCDGs of mouse multipotent adult germline stem cells can enter and progress through meiosis to form haploid male germ cells in vitro. Differentiation 2010;80:184194.

13 Eichmann A, Corbel C, Nataf V, Vaigot P, Breant C, Le Douarin NM: Ligand-dependent development of the endothelial and hemopoietic lineages from embryonic mesodermal cells expressing vascular endothelial growth factor receptor 2. Proc Natl Acad Sci USA 1997;94:5141-5146.

14 Yang L, Soonpaa MH, Adler ED, et al: Human cardiovascular progenitor cells develop from a KDR+ embryonic-stem-cell-derived population. Nature 2008;453:524-528.

15 Kattman SJ, Huber TL, Keller GM: Multipotent Flk-1+ cardiovascular progenitor cells give rise to the cardiomyocyte, endothelial, and vascular smooth muscle lineages. Dev Cell 2006; 11:723-732.

16 Moretti A, Caron L, Nakano A, et al: Multipotent embryonic Isl1+ progenitor cells lead to cardiac, smooth muscle, and endothelial cell diversification. Cell 2006;127:11511165.

17 Wu SM, Fujiwara Y, Cibulsky SM, et al: Developmental origin of a bipotential myocardial and smooth muscle cell precursor in the mammalian heart. Cell 2006;127:11371150.

18 Guan K, Nayernia K, Maier LS, et al: Pluripotency of spermatogonial stem cells from adult mouse testis. Nature 2006;440:11991203.

19 Livak KJ, Schmittgen TD: Analysis of relative gene expression data using real-time quantitative PCR and the 2(-Delta Delta C(T)) method. Methods 2001;25:402-408.
20 Heida NM, Leifheit-Nestler M, Schroeter MR, et al: Leptin enhances the potency of circulating angiogenic cells via src kinase and integrin (alpha)vbeta5: implications for angiogenesis in human obesity. Arterioscler Thromb Vasc Biol 2010;30:200-206.

21 Laib AM, Bartol A, Alajati A, Korff T, Weber $\mathrm{H}$, Augustin HG: Spheroid-based human endothelial cell microvessel formation in vivo. Nat Protoc 2009;4:1202-1215.

22 Yang X, Cepko CL: Flk-1, a receptor for vascular endothelial growth factor (VEGF), is expressed by retinal progenitor cells. J Neurosci 1996;16:6089-6099.

-23 Asahara T, Murohara T, Sullivan A, et al: Isolation of putative progenitor endothelial cells for angiogenesis. Science 1997;275:964-967.

24 Kalka C, Masuda H, Takahashi T, et al: Transplantation of ex vivo expanded endothelial progenitor cells for therapeutic neovascularization. Proc Natl Acad Sci USA 2000;97:3422-3427.

25 Lara-Hernandez R, Lozano-Vilardell P, Blanes P, Torreguitart-Mirada N, Galmes A, Besalduch J: Safety and efficacy of therapeutic angiogenesis as a novel treatment in patients with critical limb ischemia. Ann Vasc Surg 2010;24:287-294.

26 Vasa M, Fichtlscherer S, Aicher A, et al: Number and migratory activity of circulating endothelial progenitor cells inversely correlate with risk factors for coronary artery disease. Circ Res 2001;89:E1-E7.

27 Li Z, Wilson KD, Smith B, et al: Functional and transcriptional characterization of human embryonic stem cell-derived endothelial cells for treatment of myocardial infarction. PLoS One 2009;4:e8443.

28 Yamamoto K, Sokabe T, Watabe T, et al: Fluid shear stress induces differentiation of Flk1-positive embryonic stem cells into vascular endothelial cells in vitro. Am J Physiol Heart Circ Physiol 2005;288:H1915-H1924. 
29 Ferreira LS, Gerecht S, Shieh HF, et al: Vascular progenitor cells isolated from human embryonic stem cells give rise to endothelialand smooth muscle-like cells and form vascular networks in vivo. Circ Res 2007;101: 286-294.

- 30 Evensen L, Micklem DR, Blois A, et al: Mural cell associated VEGF is required for organotypic vessel formation. PLoS One 2009; 4:e5798.

-31 Vodyanik MA, Bork JA, Thomson JA, Slukvin II: Human embryonic stem cell-derived CD34+ cells: efficient production in the coculture with OP9 stromal cells and analysis of lymphohematopoietic potential. Blood 2005; 105:617-626.

- 32 Nakano T, Kodama H, Honjo T: Generation of lymphohematopoietic cells from embryonic stem cells in culture. Science 1994;265: 1098-1101.

33 Hirashima M, Kataoka H, Nishikawa S, Matsuyoshi N, Nishikawa S: Maturation of embryonic stem cells into endothelial cells in an in vitro model of vasculogenesis. Blood 1999; 93:1253-1263.
34 Zhang WJ, Park C, Arentson E, Choi K: Modulation of hematopoietic and endothelial cell differentiation from mouse embryonic stem cells by different culture conditions. Blood 2005;105:111-114.

35 Gerecht-Nir S, Ziskind A, Cohen S, Itskovitz-Eldor J: Human embryonic stem cells as an in vitro model for human vascular development and the induction of vascular differentiation. Lab Invest 2003;83:1811-1820.

36 Nishikawa SI, Nishikawa S, Hirashima M, Matsuyoshi N, Kodama H: Progressive lineage analysis by cell sorting and culture identifies FLK1+VE-cadherin+ cells at a diverging point of endothelial and hemopoietic lineages. Development 1998;125:17471757.

37 Wijelath ES, Rahman S, Murray J, Patel Y, Savidge G, Sobel M: Fibronectin promotes VEGF-induced CD34 cell differentiation into endothelial cells. J Vasc Surg 2004;39: 655-660.
8 Schuh AC, Faloon P, Hu QL, Bhimani M, Choi K: In vitro hematopoietic and endothelial potential of Flk-1(-/-) embryonic stem cells and embryos. Proc Natl Acad Sci USA 1999;96:2159-2164.

39 Furuta C, Ema H, Takayanagi S, et al: Discordant developmental waves of angioblasts and hemangioblasts in the early gastrulating mouse embryo. Development 2006; 133: 2771-2779.

40 Baba S, Heike T, Umeda K, et al: Generation of cardiac and endothelial cells from neonatal mouse testis-derived multipotent germline stem cells. Stem Cells 2007;25:13751383.

41 Suzuki H, Shibata R, Kito T, et al: Therapeutic angiogenesis by transplantation of induced pluripotent stem cell-derived Flk-1 positive cells. BMC Cell Biol 2010;11:72.

42 Narazaki G, Uosaki H, Teranishi M, et al: Directed and systematic differentiation of cardiovascular cells from mouse induced pluripotent stem cells. Circulation 2008;118: 498-506. 